\title{
Waste Management in Crude Oil Processing: Crude Oil Dehydration and Desalting
}

Hussein K Abdel-Aal ${ }^{1^{*}}$, Khaled Zohdy ${ }^{2}$ and Maha Abdelkreem ${ }^{2}$

${ }^{1}$ National Research Centre, Cairo, Egypt

${ }^{2}$ Department of Chemical Engineering, Higher Technological Institute, Tenth of Ramadan City, Egypt

\begin{abstract}
Some of the techniques that are proposed for waste management would include: modifications in process design or in used process equipment; choosing alternative approaches or routes for a given process; and recycling. Such methods are recommended in order to mitigate waste formation. Our main aim in this paper is to examine in details crude oil treatment, which involves dehydration and desalting in order to unearth and seize opportunities for waste minimization. In addition, some problems that would lead to waste formation are identified, and their solutions are recommended. Some factors that are relevant to waste formation are investigated. They include: desalting temperature, wash water ratio (dilution water), and type of de-emulsifiers.
\end{abstract}

\section{Keywords: Waste; Crude oil}

\section{Introduction}

The generation of wastes that result in the oil industry, is an inevitable consequence of the processing of crude oil, both in field surface operations and in oil refineries. Handling of crude oil mixtures, once produced, is subjected first, to what is known as surface petroleum operations (SPO). These field processing operations cover the myriad procedure required to handle the crude oil mixture between the well head and the delivery points for refining operations and other usages as shown next in Figure 1.

Oil dehydration and emulsion treatment followed by desalting are significant processes to be carried out; as part of the surface operations in field processing of crude oil mixtures as shown in Figure 2.

\section{Approach of Handling Crude Oil and Sources of Wastes}

The preliminary crude oil treatment, prior to the refining, involves oil dehydration followed by desalting. These two steps known as crude treatment are the main source of wastes produced within this stage (dehydration/desalting).

When it comes to the initial step in handling a crude oil mixture, it is subjected first to what is known as wet-crude handling-facilities. Crude oil, once produced, may contain up to $15 \%$ water, which may exist in an emulsified form. A dual function is the main objective of the dehydration step: to ensure that the remaining free water is totally removed from the bulk of oil and to apply whatever methods are necessary to break the oil emulsion. In general, free water removed by gravity in the separator is limited to large water droplets. Oil stream leaving the separator would normally contain free water droplets that are smaller in size, in addition to the water emulsified in oil [1-6].

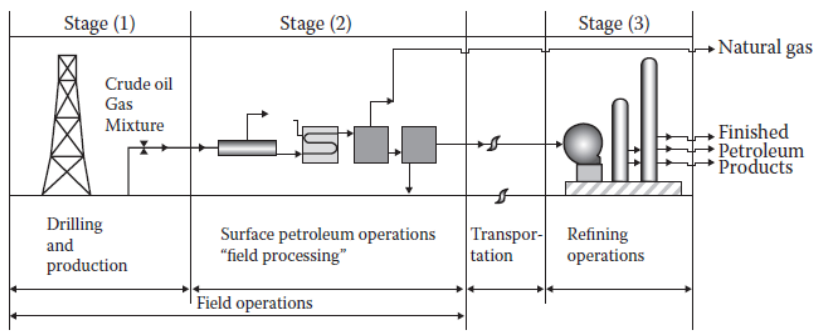

Figure 1: Main three oil operations.
Produced crude oil contains sediment and produced water, known as Basic Sediments \& Water (BS\&W), salt, and other impurities. These are readily removed from the crude oil through this crude oil treatment stage (dehydration/desalting). Produced water containing the solids and impurities is discharged to the effluent water treatment system (waste treatment facilities). Clean, dehydrated oil flows from the top of the vessel. Depending on the salt specifications, a combination of dehydrator followed by a desalting unit may be required.

The role played by adding chemicals to break crude oil-emulsions is very influential in waste formation. These chemicals act as deemulsifiers; once absorbed on the water-oil interface, they will rupture the stabilizing film surrounding the oil drops, hence the emulsions are broken.

The removal of salt from crude oil is recommended for refinery feed stocks, if the salt content exceeds 20 PTB (pounds of salt, expressed as equivalent sodium chloride, per thousand barrels of oil). Salt in

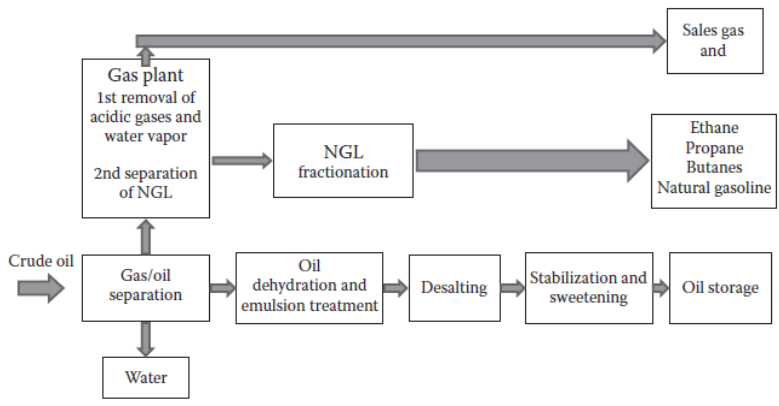

Figure 2: Field processing of crude oil mixtures.

*Corresponding author: Hussein K Abdel-Aal, National Research Centre, Cairo, Egypt, Tel: 20237499028; Fax: 20237499028; E-mail: habdelaal@link.net

Received January 15, 2018; Accepted January 30, 2018; Published February 06,2018

Citation: Abdel-Aal HK, Zohdy K, Abdelkreem M (2018) Waste Management in Crude Oil Processing: Crude Oil Dehydration and Desalting. Int J Waste Resour 8: 326. doi: $10.4172 / 2252-5211.1000326$

Copyright: @ 2018 Abdel-Aal HK, et al. This is an open-access article distributed under the terms of the Creative Commons Attribution License, which permits unrestricted use, distribution, and reproduction in any medium, provided the original author and source are credited. 
crude oil exists as dissolved inorganic compounds in the remnant water found in the oil. This remnant water is known as brine. These salt drops are dispersed within the oil. It presents serious corrosion and scaling problems and must be removed by desalting.

Electrostatic desalting is generally used, whether employed for oil field production dehydration and desalting or at oil refineries. It is recommended to facilitate the removal of inorganic chlorides and water-soluble contaminants from crude oil. For refinery applications, desalting is a must for the removal of these water-soluble compounds in order to avoid corrosion-damage to downstream distillation processes [7-10].

The most concerns of the impurities in crude oil are listed as follows:

- Inorganic salts: Crude oil containing these inorganic salts when heated in pre-heat exchangers and heaters, will lead to the decomposition of these salts. As a result, hydrogen chloride gas is formed which condenses to liquid hydrochloric acid at overhead system of distillation columns causing damages and corrosion of equipment.

- Corrosion control: Has to be applied in order to fight corrosion, however, the byproduct from the corrosion control of oil equipment consists of particulate iron sulfide and oxide. This leads to the precipitation of these waste products on heat exchanger trains, tower trays, and heater tubes causing serious fouling effects in heat transfer.

- The sand/silt: These materials can cause significant damage to pumps and pipes that results in by abrasion or erosion.

One can sum up the source and the type of wastes resulting from these processes by the following sketch (Figure 3 ).

(1) Free water (Water in crude) plus other impurities

(2) Desalter-wash -water. It contains: salt, sludge, rust, clay, and varying amounts of emulsified oil (oil-under carry)

(3) Gas out

(4) Dilution water for desalter

(5) Treated and desalted oil to refining

Waste water plant: (WWP): All refineries use some system of waste water treatment facilities for water effluents in order to return them in a safe mode either to the environment or to be reused in the refinery. The design of waste water treatment plants differs in many aspects and get complicated as a function is the refinery pollutants and chemicals to be disposed of. Waste treatment processes employed by refineries vary from case to case. However, some basic units are used. They generally include neutralizers, oil/water separators, settling chambers and clarifiers $[11,12]$.

Next, let us examine in details crude oil desalting process in order to unearth and seize opportunities for waste minimization. In addition, the following factors should be considered along this line:-

- Choosing the right process among other alternative ones.

- Modifications in process design or in used process equipment.

- Choosing alternative approaches or routes for a given process.

- Recycling policy within the refinery.

\section{Desalting of Crude Oil}

\section{Background}

The removal of salts found in the form of what we may call "remnant brine" is carried out in the desalting process. This will reduce the salt content in the crude oil to the acceptable limits of 15 to $20 \mathrm{PTB}$ (pounds of salt, expressed as equivalent sodium chloride, per thousand barrels of oil). The removal of salt from crude oil for refinery feed stocks is must. This is particularly true if the salt content exceeds the limit of 20 PTB. The most economical place for the desalting process is usually in the refinery. In addition, when marketing or pipeline requirements are imposed, field plants are employed in order to desalt the oil prior to shipping. The desalting principals apply are the same whether desalting takes place at the refinery or in the field.

The remnant brine could be defined as that part of the salty water that comes with the oil. It cannot be reduced any further by the dehydration methods and is referred to as basic sediments and water (BS\&W). As defined before this remnant water exists in the crude oil as a dispersion of very fine droplets highly emulsified in the bulk of oil. The main mineral salts found are the chlorides of sodium, calcium, and magnesium

\section{Theoretical Aspects}

Salt in crude oil is in most cases found dissolved in the remnant water within the oil. It is established that the amount of salt found in crude oil is attributed to two factors:

- The quantity of remnant water that is left in oil after normal dehydration.

- The salinity or the initial concentration of salt in the source of this water

Desalting of crude oil will eliminate or minimize problems resulting from the presence of mineral salts in crude oil. In other words, one would consider the main function of the desalter is to remove salts soluble in water from the crude oil. However, many other contaminants such as clay, silt, rust, and other debris also need to be removed.

It should be stated that the salts contain some metals that can poison catalysts used in the process of refining are dissolved in the water phase. These salts often deposit chlorides on the heat transfer equipment of the distillation units and cause fouling effects. In addition, some chlorides will decompose under high temperature, forming corrosive hydrochloric acid:

$$
\mathrm{MgCl}_{2}(\mathrm{aq}) \text { High temp } \rightarrow \mathrm{Mg}(\mathrm{OH})_{2}+\mathrm{HCl}
$$

\section{Desalting Process}

A two-stage system (a dehydration stage and a desalting stage) is recommended is shown in Figure 4. Emphasis is placed on electrostatic desalting of crude oil. The effect of operating parameters in the desalting operation is discussed.

Wash water, also called dilution water, is mixed with the crude oil coming from the dehydration stage. The wash water, which could be either fresh water, or water with lower salinity than the remnant water, mixes with the remnant water, thus diluting its salt concentration. The mixing results in the formation of a water-oil emulsion. The oil (and emulsion) is then dehydrated using the dehydration technique. The separated water is disposed of through the field-produced water treatment and disposal system. In the two-stage desalting system, as shown in Figure 4, dilution water is added in the second stage and all, or part, of the disposed water in the second stage is recycled and used as the dilution water for the first desalting stage. Two-stage desalting systems are normally used to minimize the wash water requirements. Economic use of water of dilution is important. 


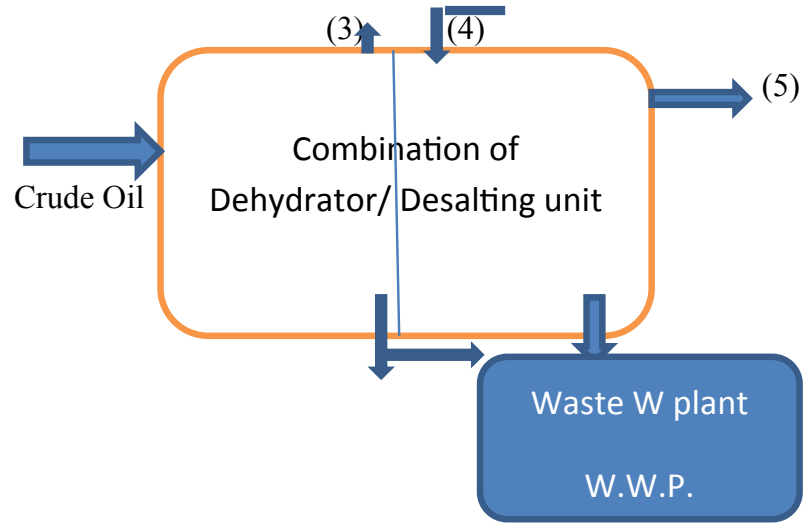

Figure 3: Structure of unit.

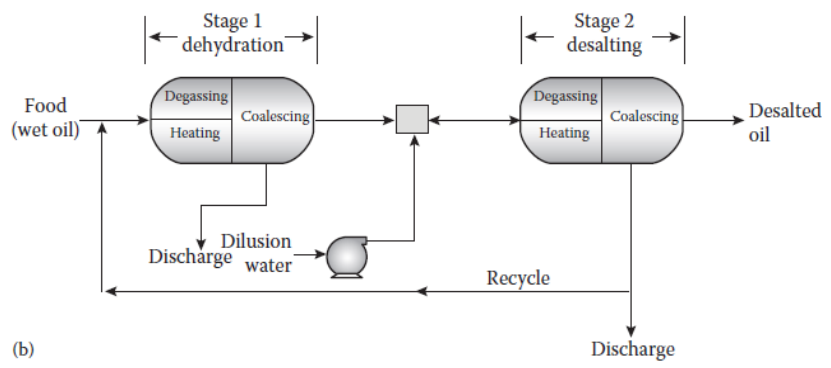

Figure 4: Two-stage desalting set up.

\begin{tabular}{|c|c|c|}
\hline \multirow{4}{*}{$\begin{array}{l}\text { A high salt content in } \\
\text { the desalted crude oil }\end{array}$} & - Feed salt content high & $\begin{array}{c}\text { - Increase the wash water } \\
\text { rate }\end{array}$ \\
\hline & -Wash water injection low & $\begin{array}{c}\text { - Reduce the crude oil } \\
\text { flow rate }\end{array}$ \\
\hline & $\begin{array}{c}\text { - Crude oil flow rate exceeds } \\
\text { the design flow } \\
\text { rate }\end{array}$ & $\begin{array}{l}\text { - Increase the mix value } \\
\text { pressure drop }\end{array}$ \\
\hline & $\begin{array}{l}\text { - Insufficient mixing of the } \\
\text { crude oil and wash } \\
\text { water }\end{array}$ & \\
\hline \multirow{4}{*}{$\begin{array}{l}\text { Oil in the desalter } \\
\text { effluent water }\end{array}$} & • "Interface" level too low & $\begin{array}{c}\text { - Increase the interface } \\
\text { level }\end{array}$ \\
\hline & $\begin{array}{l}\text { - Wide emulsion band at the } \\
\text { "interface" }\end{array}$ & $\begin{array}{l}\text { - Inject a chemical or } \\
\text { dump the emulsion }\end{array}$ \\
\hline & $\begin{array}{l}\text { - Excessive crude oil wash } \\
\text { water mixing }\end{array}$ & $\begin{array}{l}\text { - Reduce the mix valve } \\
\text { pressure drop }\end{array}$ \\
\hline & -Poor wash water quality & $\begin{array}{c}\text { - Check for any waste in } \\
\text { the wash water } \\
\text { source }\end{array}$ \\
\hline \multirow{3}{*}{$\begin{array}{l}\text { High water carry over in } \\
\text { desalted crude oil }\end{array}$} & - Crude temperature too low & \\
\hline & $\begin{array}{c}\text { - Wash water flow rate too } \\
\text { high }\end{array}$ & $\begin{array}{c}\text { - Reduce the wash water } \\
\text { flow rate and commence } \\
\text { or increase chemical } \\
\text { injection }\end{array}$ \\
\hline & $\begin{array}{l}\text { - Excessive formation water } \\
\text { in the crude oil }\end{array}$ & $\begin{array}{l}\text { - Reduce the interface } \\
\text { level and check the } \\
\text { effluent water valve }\end{array}$ \\
\hline
\end{tabular}

Table 1: Solutions for minimizing waste.
The mixing step in the desalting of crude oil is normally accomplished by pumping the crude oil (which is the continuous phase) and wash water (which is the dispersed phase) separately through a mixing device. The usual mixing device is simply a throttling valve. The degree of mixing depends on the interfacial area produced between the two phases. Higher interfacial area will cause a high degree of mixing. A useful device for such a purpose is the application of multiple-orificeplate mixers. It all depends on the intimate mixing of remnant water with dilution water, in order to maximize the desalting operation.

\section{Conclusions and Remedial Measures}

To start with, we should keep in mind the "Waste Hierarchy" that consists of the three R's: Reduce, Reuse and Recycle; all help to cut down on the amount of waste we throw away. These four R's meant to conserve our natural resources and minimize energy consumption. In addition, saving of capital spent by industry for disposing of wastes could be eliminated.

As presented before, dewatering followed by desalting of crude oil is a significant process to be carried out by the oil industry. It is a key process for upstream operation of crude distillation units; for the removal of undesirable constituents including all types of mineral salts. The salt content of crude oil (PTB) is reduced, to meet desired specification as well. Waste mitigation for crude oil desalting system can be very challenging.

The following remedial measures and actions are to be considered:

- Electrical desalting: Water-crude interface level in the separators should be kept constant; any changes will upset the electrical field and influence electrical coalescence of water drops, hence male performance may lead to waste products of crude oil; be carried away with separated water.

- Desalting temperature: Temperature affects water droplet settling through its effect on oil physical properties, in particular oil viscosity. Heavier crude oils require higher desalting temperatures in order to keep products on specification and to minimize waste products.

- Wash water ratio: Heavy crudes require a high wash water ratio to increase electrical coalescence otherwise, residual products will be formed, containing higher salt ratio.

- Pressure drop across the mixing valve: A high-pressure-drop operation results in a good mixing between wash water and the emulsion leading to a decrease in the salt content in the bulk of the oil phase. On the other hand, if the pressure drop is excessive, the formed emulsion may get very tight and hard to break. The optimum pressure drop is estimated to be about 1.5 bar for light crudes and 0.5 bar for heavy crudes.

- Types of de-emulsifiers: De-emulsifiers are added to aid in complete electrostatic coalescence and settling of emulsified oil drops, hence and oil desalting. These de-emulsifiers are important to use, especially when heavy crudes are processed. Recommended doses to use range between 3 and $10 \mathrm{ppm}$ of the crude oil.

- The following is a list to identify some problems in the desalting of oil that cause waste formation and proposes remedial solutions for them (Table 1):

Wastes to wealth: Streams leaving the dehydrator/desalter should be carefully monitored. Waste Water Plant plays a crucial role for the 
Citation: Abdel-Aal HK, Zohdy K, Abdelkreem M (2018) Waste Management in Crude Oil Processing: Crude Oil Dehydration and Desalting. Int J Waste Resour 8: 326. doi: 10.4172/2252-5211.1000326

Page 4 of 4

treatment of waste products to convert them from wastes to wealth.

It should be emphasized that a balance must be maintained between the variables involved in the desalting process which include:

- The desired mixing intensity,

- Wash water quality, and quantity (water of dilution)

- Chemical demulsifies and other parameters

This balance could be described as a sensitive one to achieve in order to obtain optimal salt content (PTB) for the treated crude. This is very much correlated to the wastes formed during a process. Monitoring the wash-water exit the desalter is a key factor to be carried out to ensure the quantity of oil-under carry. Wash water, used for dilution should be carefully controlled. It is estimated to be in the range of $2-5 \%$ of the crude oil processed to be desalted.

\section{References}

1. Abdel-Aal HK, Aggour M, Fahim MA (2003) Petroleum and gas field processing (1st edn.). Taylor \& Francis, CRC Press, Florida, USA.

2. Abdel-Aal HK, Aggour M, Fahim MA (2015) Petroleum and gas field processing (2nd edn.). Taylor \& Francis, CRC Press, Florida, USA

3. Abdel-Aal HK, Shaikh AA (1977) Desalting of oil using multiple orifice mixers An empirical correlation for the water of dilution. Presented at the Third Iranian Congress of Chemical Engineering.

4. Abdel-Aal HK, Shalabi MA (1996) Noncatalytic partial oxidation of sour natural gas versus catalytic steam reforming of sweet natural gas. Ind Eng Chem Res 35: 1785-1787.

5. Abdel-Aal HK, Alsahlawi MA (2014) Petroleum Economics and Engineerin (3rd edn.). Taylor \& Francis/CRC Press, Florida, USA.

6. American Petroleum Institute (1976) Primer of oil and gas production. American Petroleum Institute, Washington, DC.

7. Dando DA (2003) A guide for reduction and disposal of waste from oil refineries CONCAWE, report no. 6/03 Brussels.

8. https://beta.extractiveshub.org/servefile/getFile/id/2843

9. https://www.scribd.com/doc/141562925/Crude-Oil-Dehydration-and-Desalting

10. http://www.kasravand.com/index.php/oil-treatment-package/crude-oil-desalter

11. https://www.scribd.com/document/65010024/03-04-Petroleum-Waste-WaterDesalter-Case-Study

12. http://www.ecomed-intl.com/waste-management-for-oilfield-operations.html 